\title{
PENGARUH CHILLER PENDINGIN PADA KEKUATAN TARIK PRODUK COR PROPELER ALUMUNIUM
}

\author{
Hera Setiawan \\ Dosen Fakultas Teknik, Program Studi Teknik Mesin \\ Universitas Muria Kudus \\ Email: herasetiawan6969@yahoo.com
}

\begin{abstract}
ABSTRAK
Penelitian ini bertujuan untuk mengetahui pengaruh chiller pendingin terhadap kekuatan tarik pada proses pengecoran propeler kapal nelayan tiga sudu dengan material alumunium. Pengecoran dilakukan dengan pasir cetak (sand casting) dan proses peleburan logam dilakukan pada dapur crusible dengan bahan bakar minyak. Teknik pengecoran dilakukan dengan pendinginan logam cor dengan chiller pendingin yang dialiri air dengan dorongan pompa. Pengujian kekuatan tarik menggunakan mesin servopulser dengan beban maksimum $2000 \mathrm{~kg}$. Hasil penelitian ini menunjukkan bahwa proses pengecoran dengan chiller pendingin pada propeler dapat meningkatkan kekuatan tarik material alumunium. Kekuatan tarik alumunium naik dari 70,1758 MPa menjadi 99,6408 MPa (41,99\%) dan $99,7574 \mathrm{MPa}(42,15 \%)$ atau rata-rata naik sebesar $42,07 \%$.
\end{abstract}

Kata kunci: alumunium, propeler, chiller, kekuatan tarik.

\section{ABSTRACT}

The aim of this work is to study the effect of chiller during the casting process three-blade propellers of fishing boats with aluminum material. The alloy material was melted on a crucible furnace with sand casting methode. Casting technique is performed by water cooling chiller, flowed with a boost pump. Tensile strength testing using servopulser machine with a maximum load of $2000 \mathrm{~kg}$. The results of this study show that the casting process with cooling chiller on the propeller can increase the tensile strength of aluminum material. The tensile strength of aluminum increased from $70.1758 \mathrm{MPa}$ to $9.6408 \mathrm{MPa}$ (41.99\%) and $99.7574 \mathrm{MPa}(42.15 \%)$ or an average increase of $42.07 \%$.

Keywords: aluminum, propeller, chiller, tensile strenght.

\section{PENDAHULUAN}

Dari hasil penelitian sebelumnya dapat diketahui bahwa teknik pembekuan searah dapat dilakukan pada pengecoran teknik pasir cetak dengan chiller pendingin dan menghasilkan struktur mikro kolumnar dendrit pada material kuningan [1,2]. Sedangkan pada penelitian ini akan dikembangkan metode tersebut untuk propeler dengan material alumunium.

Material alumunium banyak digunakan pada proses pengecoran propeler karena harganya yang relatif murah dibandingkan dengan kuningan dan lebih mudah didapat. Alumunium yang digunakan adalah alumunium daur ulang. Gambar 1 menunjukkan diagram fasa terner Al-Si-Fe dan fase biner Al-Cu [3,4].

Pengecoran logam merupakan salah satu ilmu pengetahuan tertua yang sudah dipelajari oleh umat manusia. Walaupun telah berumur sangat tua, ilmu pengecoran logam terus berkembang dengan pesat [2]. Berbagai macam teknik dan metode pengecoran logam telah ditemukan dan terus disempurnakan, diantaranya adalah centrifugal casting, investment casting, dan sand casting serta masih banyak lagi metode-metode lainnya [3,4,5].
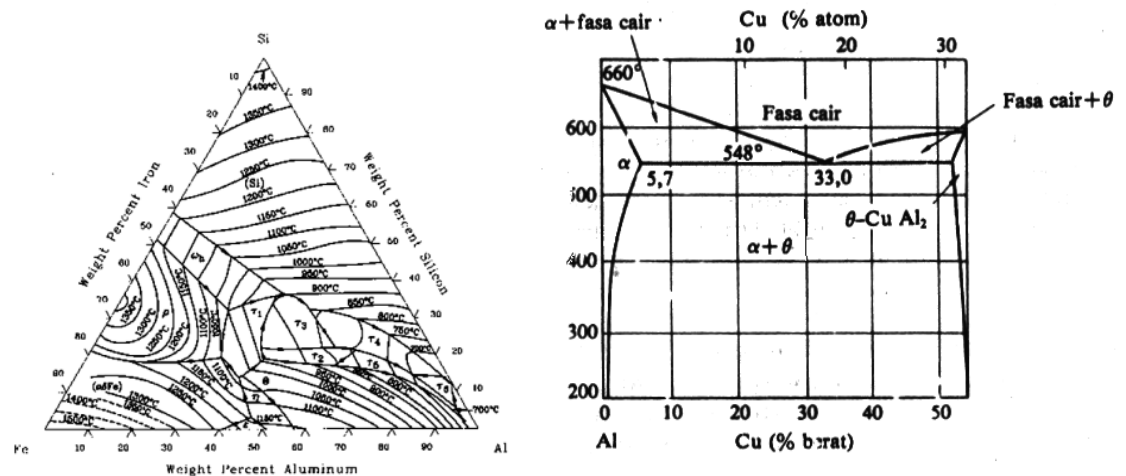

Gambar 1. Diagram fase terner Al-Si-Fe dan diagram fase biner Al-Cu [3,4] 
Industri pengecoran logam tumbuh seiring dengan perkembangan teknik dan metode pengecoran, berbagai model produk cor membanjiri pasar domestik [5]. Produk cor banyak dijumpai mulai dari perabotan rumah tangga, komponen otomotif, pompa air sampai propeler kapal seperti yang terlihat pada gambar 2 dibawah.
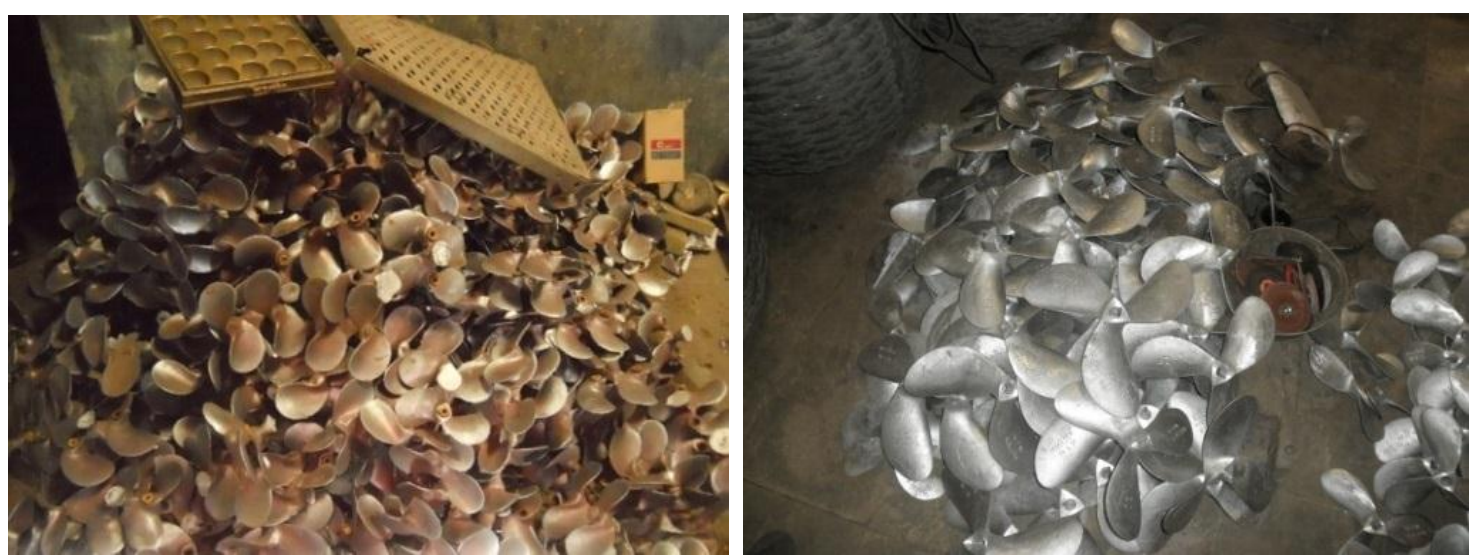

Gambar 2. Produk propeler untuk kapal nelayan dari UMKM - Juwana

Sentra-sentra industri pengecoran usaha mikro kecil dan menengah (UMKM) banyak tersebar di Propinsi Jawa Tengah seperti Klaten, Pati, Tegal dan Surakarta. Salah satu sentra industri logam khususnya pengecoran adalah Kecamatan Juwana di Kabupaten Pati Jawa Tengah. Tidak kurang dari 12 pengrajin dalam skala UMKM menekuni pekerjaan pengecoran logam dari bahan aluminium maupun kuningan. Beberapa industri menengah dengan produk yang cukup komplek yaitu : UMKM Citra Widi Mandiri, Timbulindo Gear, Yamusu, Indogas Maju Saputra, Barokah Jaya Abadi dan KTM. Salah satu produk yang dibuat dan telah dipasarkan untuk industri galangan kapal nasional adalah propeler (baling-baling kapal). UMKM pengecoran logam ini juga telah menjalin kemitraan dengan PT. National Gobel, Panasonic, Pindad Material, PT. Pura Box dan PT. Galangan Kapal [6].

Permintaan pasar akan produk logam cor yang prospektif dan luas ini, kurang di imbangi dengan peningkatan kualitas produk. Ironisnya walaupun banyak industri cor di tanah air, produk logam cor dari pengrajin lokal masih kalah bersaing dengan produk impor baik dari sisi kualitas dan harga. Hal ini merupakan tantangan yang harus segera dibenahi, agar dapat bersaing dipasar domestik, dalam negeri maupun luar negeri.

Upaya meningkatkan kualitas produk menjadi prioritas utama dalam upaya meningkatkan daya saing produk di pasar domestik maupun global. Produk yang berkualitas tentu dihasilkan dari pemilihan bahan baku yang baik, penguasaan teknik produksi, serta pengujian kualitas yang melekat.

Pada penelitian ini akan dilakukan pengujian kekerasan propeler alumunium hasil pengecoran produk UMKM dari Juana Pati. Propeler yang merupakan salah satu komponen sistem penggerak kapal sangat menentukan keberhasilan rancang bangun kapal. Kualitas produk cor propeler sangat ditentukan oleh keunggulan sifat mekanisnya, hal ini masih dikeluhkan oleh UMKM dan konsumen pengguna produk propeler. Upaya memperbaiki sifat mekanis tersebut selain dari pemilihan bahan baku (raw material) dan pengaturan komposisi paduan, juga sangat ditentukan oleh proses dan teknik pengecoran yang akan mempengaruhi bentuk mikrostruktur logam cor. Sebagaimana diketahui sebelum proses pembekuan akan didahului oleh proses pengintian untuk selanjutnya terbentuk butir (crystal) dengan batas butir (grain boundary).

Produk cor seperti propeler kapal dan sudu-sudu turbin sangat membutuhkan orientasi butir searah sehingga mampu menahan beban aksial dan memiliki kekuatan mulur yang tinggi serta tahan terhadap beban berulang atau retak fatik [5,7].

Pengujian kekuatan tarik dilakukan dengan mesin Universal Testing Machine (Servopulser), seperti yang terlihat pada gambar 3, dengan beban maksimal yang digunakan $2000 \mathrm{~kg}$. Ukuran spesimen uji tarik disesuaikan dengan standar JIS Z2201 seperti yang terlihat pada gambar 4. 




Gambar 3. Alat uji kekuatan tarik



Gambar 4. Dimensi spesimen uji tarik JIZ Z2202

\section{METODOLOGI PENELITIAN}

Penelitian ini dilakukan dengan diagram alir seperti yang terlhat pada gambar 5. Material yang digunakan pada penelitian ini adalah alumunium daur ulang berupa propeler kapal nelayan tiga sudu hasil pengecoran produk UMKM dari Juana Pati. Proses peleburan logam kuningan menggunakan dapur crucible menggunakan bahan bakar minyak dan pengecoran dengan pasir cetak (sand casting) dengan pola cetakan dari logam dan bingkai cetakan (frame) dari kayu seperti yang terlihat terlihat pada gambar 6 dan gambar 7.

Pengujian komposisi paduan logam alumunium dengan spektrometer digunakan untuk mengetahui kandungan unsur kimia yang terdapat dalam logam tersebut. Selanjutnya dengan menggunakan acuan diagram fase biner paduan $\mathrm{Al}-\mathrm{Cu}$ atau fase terner $\mathrm{Al}-\mathrm{Si}-\mathrm{Fe}$ dapat ditentukan berapa temperatur untuk mencapai titik liquidus (melting point). Hal ini penting untuk menghindari temperatur peleburan berlebih yang justru merusak cairan logam cor.

Pengujian dilakukan menggunakan mesin Universal Testing Machine (Servopulser), dengan pembebanan maksimum sebesar $2000 \mathrm{~kg}$. Ukuran spesimen uji tarik disesuaikan dengan standar JIS Z2201 seperti yang terlihat pada gambar 4 dengan merubah panjang seksi uji (Lo) dari 12,5 $\mathrm{mm}$ menjadi $25 \mathrm{~mm}$ dan tebal (t) dan lebar (w) seksi uji dari $3,1 \mathrm{~mm}$ menjadi sekitar $5 \mathrm{~mm}$.

Untuk melihat struktur mikro digunakan mikroskop optik logam dengan perbesaran 200 kali. Pengujian kekuatan tarik dilakukan dengan Universal Testing Machine. 


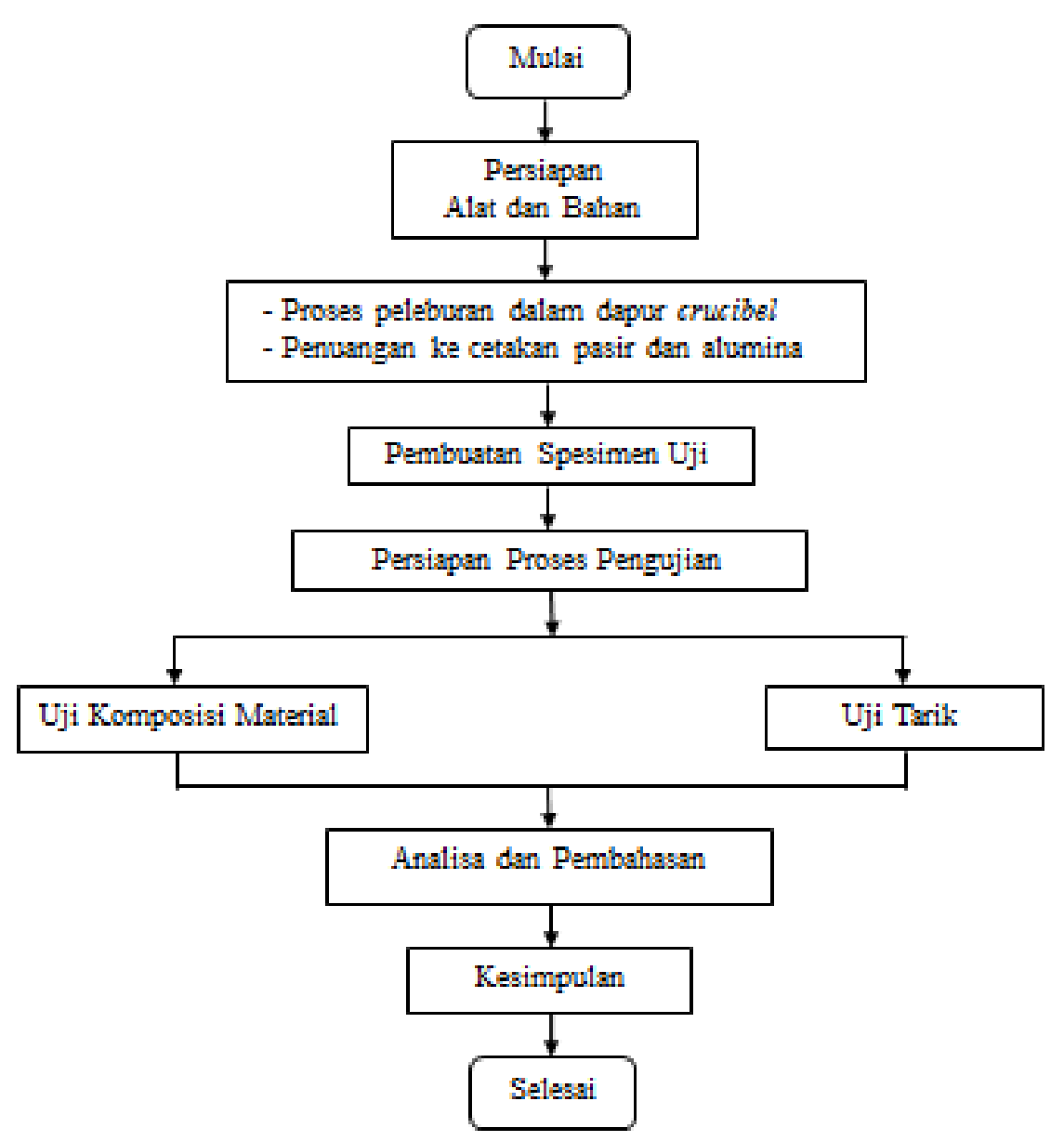

Gambar 5. Diagram alir penelitian

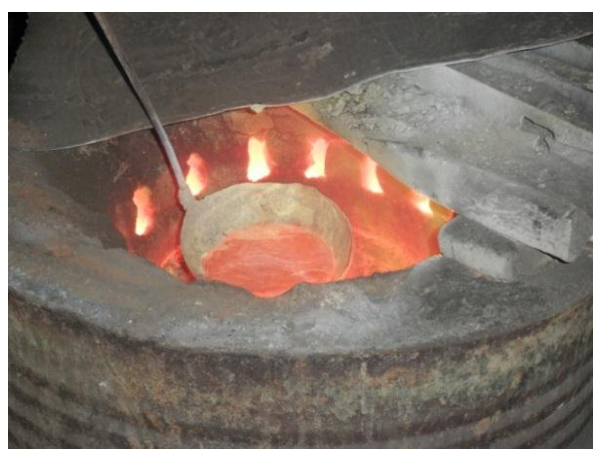

Gambar 6. Peleburan logam alumunium dengan dapur crucible

Teknik pembekuan searah dilakukan dengan mengalirkan air pendingin ke chiller dengan dorongan pompa pada saat penuangan logam alumunium dengan pengecoran pasir cetak seperti yang terlihat pada gambar 7 . Langkah pengecoran propeler dengan metode pembekuan searah (menggunakan chiller sebagai media pendingin) :

1. Memasangkan pola cetakan pada bingkai bagian drag.

2. Menaburkan bedak / tepung halus diatas permukaan pola, dengan cara ditaburkan menggunakan kain yang dibungkus.

3. Memasukkan pasir cetakan kedalam bingkai cetakan bagian drag dengan cara ditumbuk agar pasir cetak tidak runtuh saat membalik bingkai.

4. Membalik bingkai cetakan drag menjadi menjadi dibawah, dan bingkai cope menjadi menjadi diatas.

5. Menaburkan bedak / tepung yang halus pada atas pola dengan cara ditaburkan hingga merata.

6. Memasangkan saluran turun pada inti.

7. Memasukan pasir cetak kedalam bingkai cetakan bagian cope, dengan cara ditumbuk.

8. Mengambil saluran turun.

9. Mengangkat bingkai cope, harus dengan hati-hati agar pasir cetak tidak runtuh. 
10. Mengambil pola cetakan.

11. Memasangkan kembali bingkai cope diatas bingkai drag.

12. Memasangan selang dan pompa pada chiller.

13. Menghidupkan pompa aquarium sebelum penuangan logam cair.

14. Menuangkan logam cor pada saluran turun, bersamaan dengan itu air bersirkulasi mengalir hingga logam cair membeku.

15. Membongar bingkai cetakan setelah logam membeku dan keras, kurang lebih 5 menit.

Hasil proses pengecoran dibersihkan dan dibuat spesimen untuk masing-masing pengujian, sesuai bentuk dan ukuran dengan standar yang digunakan.

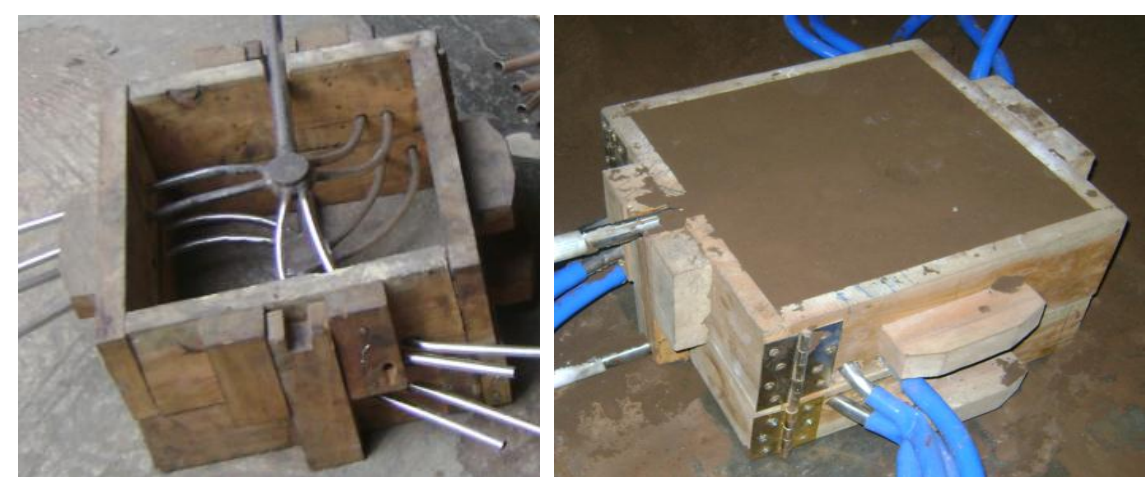

Gambar 7. Proses pengecoran cetakan pasir dengan chiller pendingin

\section{HASIL PENELITIAN DAN PEMBAHASAN}

Hasil proses pengecoran propeler alumunium adalah seperti yang terlihat pada gambar 8 .
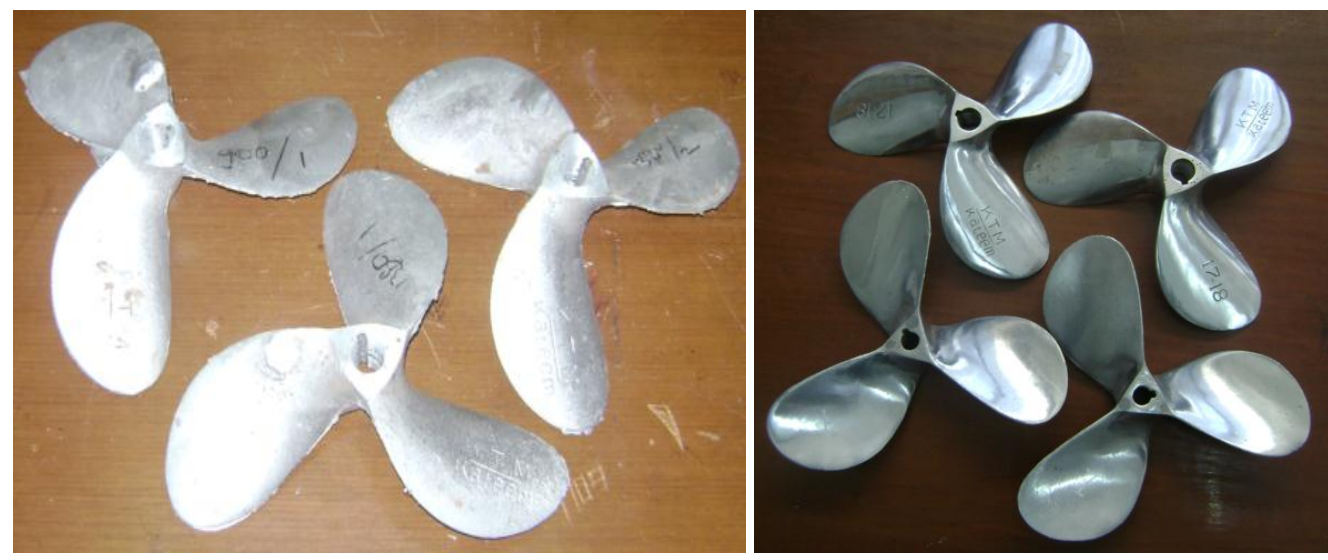

Gambar 8. Hasil pengecoran sebelum dan setelah proses finishing

\subsection{Komposisi Kimia}

Tabel 1 menunjukkan komposisi kimia material alumunium propeler kapal yang digunakan pada penelitian ini, seperti yang biasa digunakan pada UMKM atau industri logam yang ada di Juwana Pati.

Tabel 1. Komposisi kimia alumunium propeler kapal

\begin{tabular}{|c|c|c|c|c|c|c|c|c|c|c|c|c|c|c|c|c|c|}
\hline \multirow{2}{*}{ №. } & \multicolumn{17}{|c|}{ Komposisi (\%) } \\
\hline & Al & $\mathrm{Si}$ & $\mathrm{Fe}$ & $\mathrm{Cu}$ & $\mathrm{Mn}$ & $\mathrm{Mg}$ & $\mathrm{Cr}$ & $\mathrm{Ni}$ & $2 n$ & $S n$ & $\mathrm{Ti}$ & $\mathrm{Pb}$ & $\mathrm{Be}$ & $\mathrm{Ca}$ & $\mathrm{Sr}$ & V & $2 r$ \\
\hline 1 & 74,3800 & 1,8600 & 0,3550 & 11,2000 & 0,7300 & 0,7460 & 0,9770 & 0,1010 & 3,6900 & 0,8370 & 0,2540 & 4,4500 & 0,0000 & 0,0872 & 0,0000 & 0,0000 & 0,3230 \\
\hline 2 & 68,0200 & 3,2800 & 0,9800 & 12,2000 & 1,3900 & 0,0000 & 0,0312 & 0,0005 & 0,0049 & 4,4700 & 0,2430 & 9,2500 & 0,0000 & 0,0416 & 0,0000 & 0,1990 & 0,0000 \\
\hline Mean & 71,2000 & 2,5700 & 0,6675 & 11,7000 & 1,0600 & 0,3730 & 0,5041 & 0,0508 & 1,8475 & 2,6535 & 0,2485 & 6,8500 & 0,0000 & 0,0644 & 0,0000 & 0,0995 & 0,1615 \\
\hline
\end{tabular}

Dari tabel 1 terlihat bahwa material adalah paduan alumunium yang mengandung komposisi ratarata kimia $\mathrm{Al}=71,2 \%, \mathrm{Cu}=11,7 \%, \mathrm{Si}=2,57 \%, \mathrm{Fe}=0,67 \%$. 


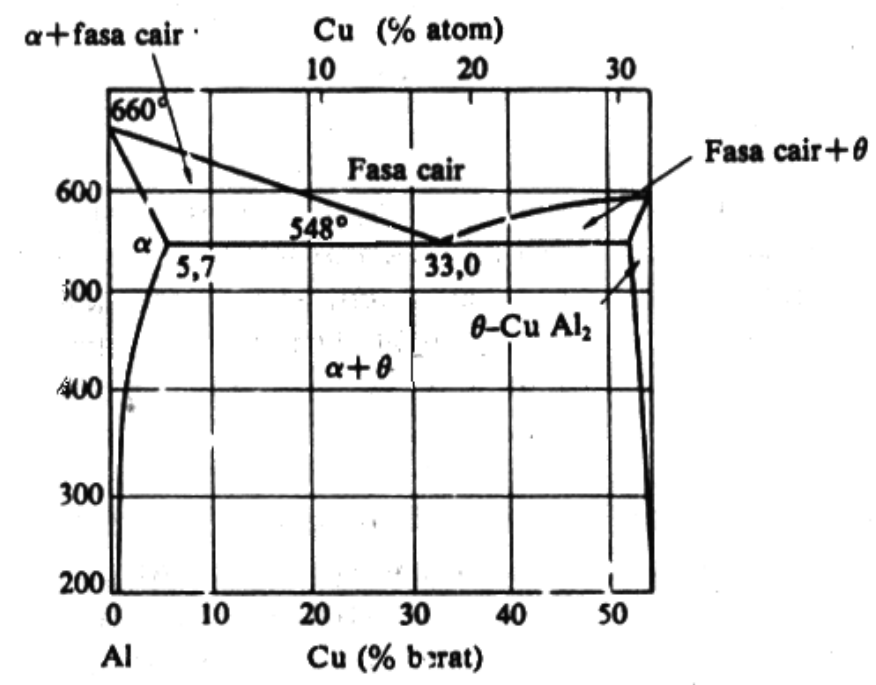

Gambar 9. Diagram fase biner Al-Cu [3,4]

Dari diagram fase biner Al-Cu seperti yang terlihat pada gambar 9 diatas, untuk alumunium dengan kandungan $11,7 \% \mathrm{Cu}$ termasuk tipe $\alpha+\theta$ dengan titik cair (liquid) sekitar $640^{\circ} \mathrm{C}$. Temperatur ini dapat dijadikan acuan untuk proses peleburan sehingga dapat dihindari temperatur peleburan berlebih yang justru merusak cairan logam cor [3,4].

\subsection{Kekuatan Tarik}

Pengujian kekuatan tarik dilakukan menggunakan mesin Servopulser dengan pembebanan maksimum sebesar $2000 \mathrm{~kg}$. Ukuran spesimen uji tarik disesuaikan dengan standar JIS Z2201 seperti yang terlihat pada gambar 4 diatas, dengan merubah panjang seksi uji (Lo) dari 12,5 mm menjadi $25 \mathrm{~mm}$ dan tebal (t) dan lebar (w) seksi uji dari 3,1 mm menjadi sekitar $5 \mathrm{~mm}$. Foto spesimen uji terlihat pada gambar 10. Grafik Beban-Regangan hasil uji tarik terlihat pada gambar 11.

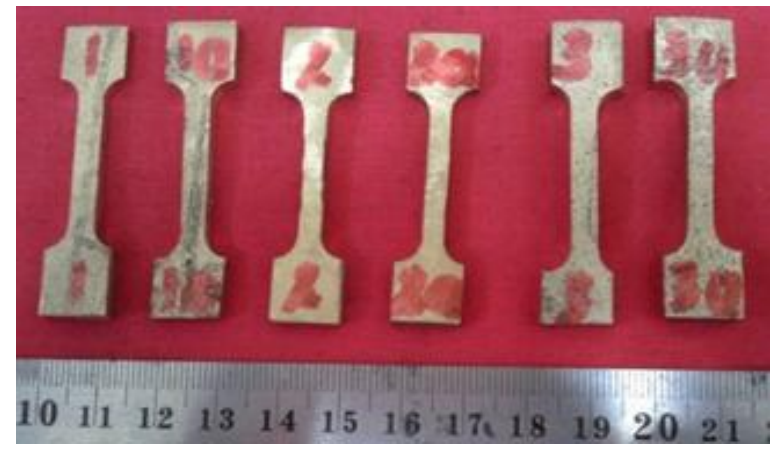

Gambar 10. Foto spesimen uji tarik

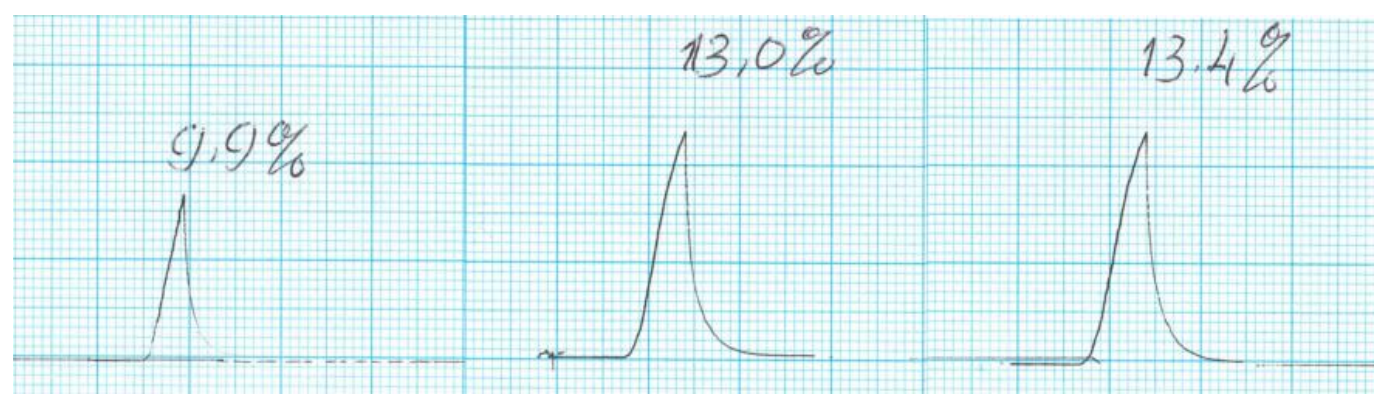

\section{Gambar 11. Grafik Beban-Regangan hasil uji tarik material alumunium}

Data hasil pengujian tarik untuk alumunium dapat dilihat pada tabel 2. Dari tabel 2 dapat dibuat grafik kekuatan tarik material seperti yang terlihat pada gambar 12. 
Tabel 2. Hasil Pengujian kekuatan tarik material alumunium

\begin{tabular}{|c|c|c|c|c|c|c|c|c|c|c|c|}
\hline \multirow{2}{*}{ No. } & \multicolumn{1}{c}{ Tebal } & Lebar & Luas & Panj & \multicolumn{3}{c|}{ Beban Mak } & \multicolumn{5}{c|}{ Kekuatan Tarik } \\
\cline { 2 - 14 } & $\mathrm{t}$ & $\mathrm{w}$ & Ao & Lo & \multicolumn{2}{c|}{$\mathrm{P}$} & \multicolumn{2}{c|}{$\sigma$} & \multicolumn{3}{c|}{ Naik } \\
\cline { 2 - 13 } & $(\mathrm{mm})$ & $(\mathrm{mm})$ & $\left(\mathrm{mm}^{2}\right)$ & $(\mathrm{mm})$ & $(\%)$ & $(\mathrm{kg})$ & $\left(\mathrm{kg} / \mathrm{mm}^{2}\right)$ & $(\mathrm{MPa})$ & $(\mathrm{MPa})$ & $(\%)$ & Rata-rata \\
\hline 1 & 4,65 & 5,95 & 27,6675 & 25 & $9,90 \%$ & 198 & 7,1564 & 70,1758 & 0,0000 & $0,00 \%$ & \\
\hline 2 & 4,45 & 5,75 & 25,5875 & 25 & $13,00 \%$ & 260 & 10,1612 & 99,6408 & 29,4651 & $41,99 \%$ & $42,07 \%$ \\
\hline 3 & 4,45 & 5,92 & 26,3440 & 25 & $13,40 \%$ & 268 & 10,1731 & 99,7574 & 29,5816 & $42,15 \%$ & \\
\hline
\end{tabular}

Hasil penelitian ini menunjukkan bahwa proses pengecoran dengan chiller pendingin pada propeler dapat meningkatkan kekuatan tarik material alumunium. Kekuatan tarik alumunium naik dari 70,1758 MPa menjadi 99,6408 MPa (41,99\%) dan 99,7574 MPa (42,15\%) atau rata-rata naik sebesar 42,07\%.

\section{Grafik Kekuatan Tarik Material}



Gambar 12. Grafik kekuatan tarik material alumunium dan peningkatannya

\section{KESIMPULAN}

Dari penelitian ini didapatkan kesimpulan sebagai berikut:

a. Teknik pembekuan searah dengan chiller pendingin dapat dilakukan pada proses pengecoran propeler kapal nelayan dengan material alumunium.

b. Teknik pembekuan searah dengan chiller pendingin dapat meningkatkan kekuatan tarik material sampai $42,07 \%$.

c. Masih perlu dilakukan penelitian lanjutan tentang teknik dan metode pada pengecoran propeler kapal nelayan, sehingga dapat meningkatkan kualitas dan daya saing produk.

\section{SARAN}

Perlu dilakukan penelitian lanjutan tentang teknik dan metode pada pengecoran propeler, sehingga dapat meningkatkan kualitas dan daya saing produk

\section{DAFTAR PUSTAKA}

[1] Setiawan, H. 2013. "Pengujian Kekuatan Tarik, Kekerasan dan Struktur Mikro Produk Cor Propeler Kuningan". SIMETRIS 3. 1, 71-79.

[2] Setiawan, H. 2014. "Pengaruh Chiller Pendingin Pada Kekerasan Produk Cor Propeler Alumunium". SIMETRIS 5. 2, 105-114.

[3] Surdia, T., dan Saito, S. (1992). Pengetahuan Bahan Teknik. Jakarta: P.T. Pradnya Paramitha.

[4] Callister Jr.,W.D., and Rethwisch, D.G., (2010). Materials Science and Engineering, An Introduction, Eight Edition, New York, USA : John Wiley \& Sons. 
[5] Brown, JR. (2001). Foseco Non-Ferrous Foundryman's Handbook, Eleveth Edition, Oxford: ButterworthHeinemann.

[6] Disperindag Pati. (2008). Profil Usaha Industri Kecil Menengah Perlogaman. Pati.

[7] Smallman, R..E., and Bishop, R.J. (1999). Modern Physical Metallurgy and Materials Engineering, Science, process, applications. Sixth Edition, Oxford: Butterworth-Heinemann. 